\title{
Percutaneous Coronary Interventions in Patients with ST-segment Elevation Myocardial Infarction and Totally Occluded Culprit Artery after Pre-hospital Thrombolysis
}

\author{
Ivan Bessonov, MD, PhD*; Vadim A. Kuznetsov, MD, PhD, FESC, FACC; \\ Igor Zyrianov, MD, PhD; Stanislav Sapozhnikov, MD \\ Tyumen Cardiology Research Center, Tomsk National Research Medical Center \\ of the Russian Academy of Sciences, the Russian Federation
}

\begin{abstract}
The aim of this study was to evaluate in-hospital outcomes of percutaneous coronary intervention (PCI) in patients with acute STEMI with completely occluded culprit artery after pre-hospital thrombolysis (PT).

Methods: Altogether 1,103 consecutive patients with STEMI admitted to the coronary care unit and submitted to PCI from January 2005 to January 2015 were included in the analysis. The clinical and angiographic characteristics, in-hospital outcomes, as well as predictors of no-reflow phenomenon were analyzed.

Results: Altogether 708 patients $(64.2 \%)$ with a completely occluded culprit artery (initial TIMI flow $\leq 1)$ were included in the analysis. Overall, 78(11\%) patients who received PCI after PT (PT-group) were compared with 630(89\%) patients who received primary PCI (PPCI-group). The rates of no-reflow $(14.1 \%$ vs $6.8 \% ; P=0.02)$ and recurrent MI $(5.1 \%$ vs $1.3 \% ; P=0.03)$ were significantly higher in the PT-group. The rates of death $(5.2 \%$ vs $5.1 \% ; P=0.61)$ and stent thrombosis $(3.8 \%$ vs $1.3 \% ; P=0.11)$, as well as MACE $(9.0 \%$ vs $7.0 \% ; P=0.52)$, were comparable between the groups. After univariate analysis, several clinical and procedural characteristics were associated with no-reflow, but only PT was associated with recurrent MI (OR=4.20; 95\% CI 1.24-14.3; $P=0.02)$. After multivariate analysis, PT remained an independent predictor of no-reflow $(\mathrm{OR}=2.53 ; 95 \% \mathrm{CI} 1.17-5.46 ; P=0.015)$

Conclusion: PCI in patients with STEMI and completely occluded culprit artery after PT was associated with higher levels of no-reflow and recurrent MI. Completely occluded culprit artery after PT was an independent predictor of no-reflow during PCI. (International Journal of Biomedicine. 2018;8(1):15-19.)
\end{abstract}

Key Words: STEMI • percutaneous coronary intervention • pre-hospital thrombolysis • totally occluded culprit artery

\begin{abstract}
Abbreviations
BMI, body mass index; CAD, coronary artery disease; CKD, chronic kidney disease; CABG, coronary artery bypass grafting; MI, myocardial infarction; MACE, major adverse cardiac events; PCI, percutaneous coronary intervention; PT, pre-hospital thrombolysis; STEMI, ST-segment elevation MI.
\end{abstract}

\section{Introduction}

Despite the reduction in time to reperfusion with pre-hospital thrombolysis (PT), about $40 \%$ of patients do not achieve culprit artery patency. ${ }^{(1)}$ In such cases, rescue percutaneous coronary interventions (PCI) reduce the risks of

*Corresponding author: Ivan Bessonov, MD, PhD. Tomsk NRMC of the RAS. Tomsk, Russia.E-mail: IvanBessnv@gmail.com recurrent MI and death compared to conservative therapy. ${ }^{(2,3)}$ Some studies show no differences between rescue and primary PCI in reducing the composite of death, shock, congestive heart failure, or reinfarction. ${ }^{(4,5)}$ However, the results of PCI in patients with a completely occluded culprit artery after PT are still insufficiently explored. We hypothesized that persistent infarct-related artery occlusion after PT can worsen the prognosis. The aim of this study was to evaluate inhospital outcomes of PCI in patients with acute STEMI with completely occluded culprit artery after PT. 


\section{Materials and Methods}

\section{Study population}

Altogether 1,103 consecutive patients with STEMI admitted to the coronary care unit and submitted to PCI at our center from January 2005 to January 2015 were included in the analysis. Some patients underwent ambulance-based, fulldose tenecteplase thrombolysis, and since 2008, PT has been performed. The decision to conduct treatment with PT was taken by an ambulance physician according to the local standard. All patients received aspirin, $300 \mathrm{mg}$, and a loading dose of the clopidogrel (300 mg or $600 \mathrm{mg}$ ) before catheterization. Patients were anticoagulated with unfractionated heparin (100 IU/kg). Coronary angiography and PCI were performed from either the femoral or radial arterial access, according to the operator's decision. Patients were managed with standard post-PCI care and appropriate secondary prevention (aspirin, clopidogrel, $\beta$-blockers, angiotensin-converting-enzyme inhibitors and statins) was commenced unless otherwise contraindicated.

\section{Clinical and procedural data}

Clinical data were obtained from the local hospital database, containing information on each PCI in STEMI patients, including demographics, baseline clinical and procedural details as well as in-hospital outcomes. All angiograms of the included patients were reviewed. An occluded culprit artery was defined as a culprit vessel with TIMI 0 to 1 flow, indicating no dye penetration or minimal dye penetration without complete vessel opacification. In patients after PT, non-invasive markers of reperfusion were evaluated and documented within 90 min after thrombolytic administration, according to hospital standard. In cases when ST resolution was partial or absent along with prolonged chest pain and absent of reperfusion arrhythmias, rescue PCIs were performed. The demographic, clinical, angiographic and in-hospital outcomes were analyzed. The composite of inhospital death, recurrent MI and stent thrombosis were defined as MACE. Recurrent MI was defined as acute MI that occurs following the initial MI within hospitalization. Periprocedural MI was considered as a part of recurrent MI.

\section{Statistical analysis}

All analyses were performed with SPSS v21.0 (SPSS Inc., Chicago, Illinois, USA). Continuous variables are presented as mean $\pm \mathrm{SD}$ and as medians (interquartile ranges). Continuous variables were compared by use of Student's unpaired t-test, or Mann-Whitney U test when data were not normally distributed. Categorical variables were expressed as numbers (percentages) and compared by Chi-squared test or Fisher's exact. To determine relationship between PT with noreflow and recurrent MI univariate analysis was performed. To assess the impact of PT on no-reflow, multivariate logistic analysis was used. Variables reaching significance, or tendency to significance, on univariate analysis $(\mathrm{p} \leq 0.1)$ were subsequently incorporated into a multivariate model. Independent variables are presented as odds ratios (OR) with $95 \%$ confidence intervals (CI). P-values $<0.05$ were considered statistically significant.

\section{Results}

Out of 1,103 patients who underwent PCI for STEMI, 207(18.8\%) received PT and 395(35.8\%) were excluded-381 because initial TIMI flow $\geq 2$ and 14 for failure of guidewire lesion crossing or stent delivery. The remaining 708 patients were included in the final analysis. Overall, 78(11\%) patients who received PCI after PT (PT-group) were compared with $630(89 \%)$ patients who received primary PCI (PPCI-group).

\section{Clinical and procedural data}

The characteristics of both patient groups are presented in Table 1. There were no differences in age, BMI, hyperlipidemia, incidence of diabetes, hypertension or CKD.

Table 1.

Baseline patient characteristics

\begin{tabular}{|c|c|c|c|c|}
\hline \multicolumn{2}{|c|}{ Variable } & PT-group & PPCI-group & $P$-value \\
\hline \multicolumn{2}{|l|}{ Age, years } & $58.3 \pm 10.6$ & $59.0 \pm 11.6$ & 0.49 \\
\hline \multicolumn{2}{|l|}{ Males, gender, n (\%) } & $63(80.8 \%)$ & $451(71.6 \%)$ & 0.09 \\
\hline \multicolumn{2}{|l|}{ BMI, $\mathrm{kg} / \mathrm{m}^{2}$} & $29.3 \pm 4.2$ & $28.9 \pm 4.9$ & 0.26 \\
\hline \multicolumn{2}{|c|}{ Current smoker, n (\%) } & $38(48.7)$ & $243(38.6)$ & 0.08 \\
\hline \multicolumn{2}{|c|}{ Hyperlipidemia, n (\%) } & $66(84.6)$ & $555(88.1)$ & 0.37 \\
\hline \multicolumn{2}{|c|}{ Diabetes mellitus, n (\%) } & $10(12.8)$ & $110(17.5)$ & 0.30 \\
\hline \multicolumn{2}{|l|}{ Hypertension, n (\%) } & $58(74.4)$ & $505(80.2)$ & 0.23 \\
\hline \multicolumn{2}{|c|}{ Previous CAD, n (\%) } & $25(32.1)$ & $229(36.3)$ & 0.46 \\
\hline \multicolumn{2}{|l|}{ Previous MI, n (\%) } & $18(23.1)$ & $99(15.7)$ & 0.10 \\
\hline \multicolumn{2}{|l|}{ Previous PCI, n (\%) } & $10(12.8)$ & $58(9.2)$ & 0.31 \\
\hline \multicolumn{2}{|c|}{ Previous CABG, n (\%) } & $1(1.3)$ & $2(0.3)$ & 0.30 \\
\hline \multicolumn{2}{|c|}{ Previous stroke, $\mathrm{n}(\%)$} & $2(2.6)$ & $40(6.3)$ & 0.14 \\
\hline \multicolumn{2}{|l|}{ CKD, n $(\%)$} & $4(5.1)$ & $39(6.2)$ & 0.48 \\
\hline \multicolumn{2}{|c|}{ Glycemia on admission, $(\mathrm{mmol} / \mathrm{l})$} & $8.6 \pm 3.0$ & $8.5 \pm 3.6$ & 0.19 \\
\hline \multirow{4}{*}{$\begin{array}{l}\text { Killip class on } \\
\text { admission, } \mathrm{n}(\%)\end{array}$} & I & $66(84.6)$ & $576(91.4)$ & \multirow{4}{*}{0.25} \\
\hline & II & $7(9.0)$ & $32(5.1)$ & \\
\hline & III & $1(1.3)$ & $3(0.5)$ & \\
\hline & IV & $4(5.1)$ & $19(3)$ & \\
\hline
\end{tabular}

Angiographic and procedural data are summarized in Table 2. There were no differences between the groups with regard to infarct-related arteries, number of stents implanted, incidence of multivessel disease, use of thrombus aspiration, predilation and a transradial approach. Glycoprotein IIb/IIIa inhibitors were used more often in the PT-group. In the PTgroup, pain-to-thrombolysis time was shorter than pain-todoor time in the PPCI-group. The median time from receiving thrombolysis to PCI was 220 (105-480) minutes. The rate of no-reflow was higher in the PT-group.

For PT-group, non-invasive markers of reperfusion were analyzed (Table 3). The absence of post-thrombotic resolution of ST elevation was detected in most patients. One-third of patients had prolonged chest pain and reperfusion arrhythmias. 
Table 2 .

\section{Angiographic and procedural outcomes}

\begin{tabular}{|c|c|c|c|}
\hline Variable & PT-group & PPCI-group & $P$-value \\
\hline Infarct artery: & \multirow[b]{2}{*}{$34(43.6)$} & \multirow[b]{2}{*}{$279(44.3)$} & \multirow[b]{2}{*}{0.91} \\
\hline $\begin{array}{l}\text { Left anterior descending, } \\
\text { n }(\%)\end{array}$ & & & \\
\hline Left circumflex, n (\%) & $85(13.5)$ & $8(10.3)$ & 0.43 \\
\hline Right, n (\%) & $240(38,1)$ & $33(42.3)$ & 0.47 \\
\hline Left main, n (\%) & $5(0.8)$ & $1(1.3)$ & 0.51 \\
\hline Multi-vessel disease, n (\%) & $26(33.3)$ & $183(29)$ & 0.43 \\
\hline $\begin{array}{l}\text { Number of stents implanted, } \\
\mathrm{n}(\%)\end{array}$ & $1.0 \pm 0.5$ & $1.1 \pm 0.5$ & 0.08 \\
\hline Predilation, n (\%) & $46(59)$ & $404(64.1)$ & 0.37 \\
\hline Drug-eluting stent, n (\%) & $22(31.4)$ & $161(27.5)$ & 0.49 \\
\hline Transradial approach, n (\%) & $43(55.1)$ & $330(52.4)$ & 0.65 \\
\hline MT, n (\%) & $4(5.1)$ & $43(6.8)$ & 0.57 \\
\hline GPI, n (\%) & $3(3.8)$ & $4(0.6)$ & 0.03 \\
\hline $\begin{array}{l}\text { Pain-to-door/pain-to- } \\
\text { thrombolysis time* }{ }^{*}, \text { min }\end{array}$ & $80[50 ; 225]$ & $120[64 ; 235]$ & 0.03 \\
\hline No-reflow, n (\%) & $11(14.1)$ & $43(6.8)$ & 0.02 \\
\hline
\end{tabular}

MT - manual thrombus aspiration; GPI - glycoprotein IIb/IIIa inhibitor; *-Pain-to-door time calculated for PPCI-group, pain-tothrombolysis time calculated for PT-group.

\section{Table 3.}

Non-invasive markers of reperfusion in PT-group

\begin{tabular}{|l|l|c|}
\hline \multicolumn{2}{|c|}{ Variable } & $\mathrm{n}(\%)$ \\
\hline \multirow{3}{*}{$\begin{array}{l}\text { Relative ST-segment } \\
\text { resolution at 90 minutes }\end{array}$} & Complete $(>70 \%)$ & $6(7.7)$ \\
\cline { 2 - 3 } & Partial $(30 \%-70 \%)$ & $17(21.8)$ \\
\cline { 2 - 3 } Chest pain & Absent $(<30 \%)$ & $55(70.5)$ \\
\hline \multirow{4}{*}{ Reperfusion arrhythmias } & Prolonged & $28(35.9)$ \\
\cline { 2 - 3 } & Absent & $50(64.1)$ \\
\cline { 2 - 3 } & AIVR & $1(1.3)$ \\
\cline { 2 - 3 } & VPB & $19(24.4)$ \\
\cline { 2 - 3 } & Absent & $53(6.4)$ \\
\hline
\end{tabular}

AIVR - accelerated idioventricular rhythm; VPB - ventricular premature beats; VF - ventricular fibrillation.

\section{In-hospital clinical outcomes}

The rate of recurrent MI was significantly higher in the PT-group (Table 4). All recurrent MIs were due to stent thrombosis in the PPCI-group. In the PT-group, one patient had a recurrent MI without stent thrombosis. A recurrent MI in this case was diagnosed by the presence of typical symptoms of acute myocardial ischemia and a fivefold re-rise of troponin T. The rates of death and stent thrombosis, as well as MACE, were comparable between the groups. After univariate analysis, several clinical and procedural characteristics were associated with no-reflow, but only PT was associated with recurrent MIs (Table 5). After multivariate analysis (Fig.1), $\mathrm{PT}$ remained an independent predictor of no-reflow $(\mathrm{OR}=2.53$; $95 \%$ CI 1.17-5.46), along with age, body mass index, previous coronary artery disease, glycemia on admission, cardinogenic shock, left main PCI, multivessel disease and pre-dilation.

Table 4.

In-hospital clinical outcomes

\begin{tabular}{|l|c|c|c|}
\hline \multicolumn{1}{|c|}{ Variable } & PT-group & PPCI-group & $P$-value \\
\hline Death, n (\%) & $4(5.1)$ & $33(5.2)$ & 0.61 \\
\hline Recurrent MI, n (\%) & $4(5.1)$ & $8(1.3)$ & 0.03 \\
\hline Stent thrombosis, n (\%) & $3(3.8)$ & $8(1.3)$ & 0.11 \\
\hline MACE, n (\%) & $7(9.0)$ & $44(7.0)$ & 0.52 \\
\hline
\end{tabular}

Table 5.

Univariate logistic analysis for no-reflow and recurrent MI

\begin{tabular}{|l|c|c|c|c|c|c|}
\hline \multirow{2}{*}{\multicolumn{1}{|c|}{ Variable }} & \multicolumn{3}{|c|}{ No-reflow } & \multicolumn{3}{c|}{ Recurrent MI } \\
\cline { 2 - 7 } & OR & $95 \%$ CI & $P$ & OR & $95 \%$ CI & $P$ \\
\hline Age (years) & 1.04 & $1.01-1.06$ & 0.05 & 1.00 & $0.95-1.05$ & 0.95 \\
\hline Male sex & 1.02 & $0.55-1.90$ & 0.95 & 0.53 & $0.11-2.42$ & 0.41 \\
\hline BMI & 1.07 & $1.01-1.12$ & 0.02 & 0.90 & $0.78-1.03$ & 0.12 \\
\hline Current smoker & 0.68 & $0.37-1.23$ & 0.20 & 1.53 & $0.49-4.80$ & 0.47 \\
\hline Hyperlipidemia & 0.68 & $0.32-1.43$ & 0.47 & 0.70 & $1.15-3.23$ & 0.64 \\
\hline Diabetes mellitus & 1.62 & $0.84-3.13$ & 0.15 & 0.98 & $0.21-4.53$ & 0.98 \\
\hline Hypertension & 1.31 & $0.63-2.75$ & 0.47 & 0.77 & $0.21-2.88$ & 0.70 \\
\hline Previous CAD & 2.21 & $1.27-3.87$ & 0.01 & 1.28 & $0.40-4.08$ & 0.67 \\
\hline Previous MI & 1.50 & $0.76-2.93$ & 0.24 & 2.58 & $0.76-8.71$ & 0.13 \\
\hline Previous PCI & 0.74 & $0.26-2.11$ & 0.57 & 0.85 & $0.12-6.71$ & 0.88 \\
\hline CKD & 2.56 & $1.08-6.06$ & 0.03 & 3.20 & $0.69-15.06$ & 0.14 \\
\hline $\begin{array}{l}\text { Glycemia on } \\
\text { admission }\end{array}$ & 1.15 & $1.08-1.22$ & $<0.001$ & 0.96 & $0.79-1.16$ & 0.64 \\
\hline $\begin{array}{l}\text { Pain-to-door/ } \\
\text { pain-to-thrombo- } \\
\text { lysis time* }\end{array}$ & 1.00 & $0.99-1.01$ & 0.76 & 0.99 & $0.94-1.03$ & 0.64 \\
\hline $\begin{array}{l}\text { Cardiogenic } \\
\text { shock }\end{array}$ & 7.41 & $2.99-18.38$ & $<0.001$ & 2.79 & $0.34-22.53$ & 0.34 \\
\hline $\begin{array}{l}\text { Left anterior } \\
\text { descending PCI }\end{array}$ & 1.01 & $0.58-1.77$ & 0.97 & 1.79 & $0.56-5.68$ & 0.33 \\
\hline $\begin{array}{l}\text { Left circumflex } \\
\text { PCI }\end{array}$ & 0.66 & $0.26-1.69$ & 0.38 & 0.60 & $0.08-4.68$ & 0.62 \\
\hline Right PCI & 0.86 & $0.48-1.53$ & 0.60 & 1.14 & $0.36-3.63$ & 0.82 \\
\hline Left main PCI & 12.77 & $2.51-64.86$ & 0.03 & - & & \\
\hline $\begin{array}{l}\text { Multi-vessel } \\
\text { disease }\end{array}$ & 2.03 & $1.16-3.56$ & 0.02 & 1.72 & $0.54-5.49$ & 0.36 \\
\hline Pre-dilation & 3.07 & $1.48-6.40$ & 0.001 & 1.74 & $0.47-6.47$ & 0.41 \\
\hline PT & $1.10-4.55$ & 0.03 & 4.20 & $1.24-14.30$ & 0.02 \\
\hline
\end{tabular}

*-Pain-to-door time calculated for PPCI-group, pain-to-thrombolysis time calculated for PT-group. 


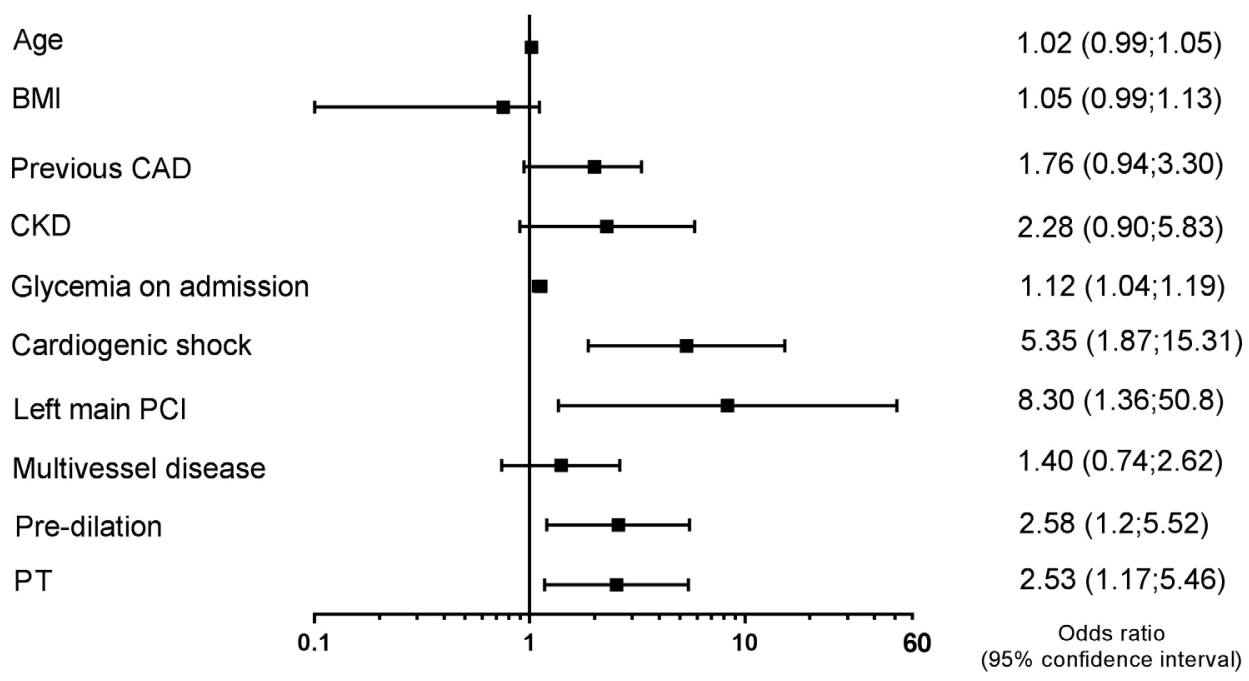

Fig. 1. Multivariate logistic analysis for no-reflow.

\section{Discussion}

Recent studies have confirmed that a pharmacoinvasive strategy in patients with STEMI may be comparable to PPCI. In a CAPTIM trial, pre-hospital fibrinolysis followed by early transfer to PCI led to 5-year survival rates similar to those of PPCI. ${ }^{(6)}$ In the 5-year analysis of the French Registry of Acute Coronary Syndrome (FAST-MI-2005), survival with a pharmacoinvasive strategy was comparable to survival with PPCI. ${ }^{(7)}$ In the registry from Belgium, the results were similar for in-hospital mortality and 1-year survival. ${ }^{(8)}$ In the STREAM study, the 30-day primary composite outcome (death, shock, congestive heart failure, or recurrent MI) was similar in the PPCI and pharmacoinvasive groups. ${ }^{(4)} \mathrm{A}$ combined analysis of the CAPTIM and WEST trials shows the advantages of the pharmacoinvasive strategy for 1 -year outcomes. ${ }^{(9)}$ In analysis of the Mayo Clinic STEMI database, fibrinolysis followed by transfer for PCI was found to be a reasonable alternative when PPCI is not readily available. ${ }^{(10)}$ But in all of these studies, cases with successful and failed thrombolysis were not analyzed separately. A pharmacoinvasive approach can be more effective than PPCI in cases when culprit artery patency is achieved. In this situation, pharmacoinvasive strategy can reduce the reperfusion time, which is especially important for patients presenting early after the onset of symptoms. ${ }^{(11,12)}$ But the incidence of complete culprit artery patency (TIMI grade 3 flow) occurred in only $55 \%$ to $60 \%$ of patients treated with PT. ${ }^{(1)}$ In our study, patients with a totally occluded culprit artery after PT had higher rates of recurrent MI and incidence of no-reflow during PCI. Potentially all of these patients could receive a primary PCI at an acceptable time. Thrombolysis in these cases increased the time to PCI.

According to our data, unsuccessful PT was an independent predictor of no-reflow during PCI. Negative effects of the no-reflow phenomenon on clinical outcomes in patients with STEMI were demonstrated in several studies. No-reflow was associated with higher mortality, poor healing of the infarct zone, and adverse remodeling with an increase in left ventricular failure. ${ }^{(13)}$ The pathological mechanisms of no-reflow include injury related to ischemia, reperfusion, endothelial dysfunction, and distal thromboembolism. ${ }^{(14)}$ Probably as a result of unsuccessful thrombolysis, components of the thrombus and atherosclerotic materials can produce small distal emboli, causing a further reduction in the coronary flow during PCI.

Several studies and meta-analyses have shown that early, routine, post-thrombolysis angiography with subsequent PCI can improve results, compared to a strategy of performing angiography and revascularization only in patients without ST-segment resolution or ongoing chest pain. ${ }^{(15-17)}$ Our data confirm this statement. After PT, $8 \%$ of patients with persistent culprit artery occlusion had complete ST-segment resolution and $22 \%$ had partial ST-segment resolution. Moreover, most of the patients had no ongoing chest pain. An early routine post-thrombolysis strategy can be particularly effective in these cases.

Our study has several limitations. Firstly, this study was retrospective, nonrandomized and had the potential of selection bias. The number of patients in the PT-group was significantly lower than in the PPCI-group. Moreover, the number of events of recurrent $\mathrm{MI}$ and no-reflow were rather small. The multivariable models are not particularly strong with such a limited number of events. The study duration was over 10 years, and practice could change during this time. In addition, the long-term results were not assessed in this study.

In conclusion, PCI in patients with STEMI and completely occluded culprit artery after PT was associated with higher levels of no-reflow and recurrent MI. Completely occluded culprit artery after PT was an independent predictor of no-reflow during PCI.

\section{Competing interests}

The authors declare that they have no competing interests. 


\section{References}

1. Topol EJ. Acute myocardial infarction: thrombolysis. Heart 2000; 83(3):122-6.

2. Ko DT, Atzema CL, Donovan LR, Graham MM, Huynh $\mathrm{T}$, So DY, et al. Rescue percutaneous coronary interventions for failed fibrinolytic therapy in ST-segment elevation myocardial infarction: a population-based study. Am Heart J. 2011;161(4):764-770.e1. doi: 10.1016/j.ahj.2010.12.016.

3. Wijeysundera HC, Vijayaraghavan R, Nallamothu BK, Foody JM, Krumholz HM, Phillips CO, et al. Rescue angioplasty or repeat fibrinolysis after failed fibrinolytic therapy for ST-segment myocardial infarction: a meta-analysis of randomized trials. J Am Coll Cardiol. 2007;49(4):422-30

4. Armstrong PW, Gershlick AH, Goldstein P, Wilcox R, Danays T, Lambert Y, et al. Fibrinolysis or primary PCI in ST-segment elevation myocardial infarction. N Engl J Med. 2013;368(15):1379-87. doi: 10.1056/NEJMoa1301092.

5. Bessonov IS, Kuznetsov VA, Zyryanov IP, Musikhina NA, Sapozhnikov SS, Takkand AG, Zateyshchikov DA. [Percutaneous Coronary Intervention in Patients With Acute Myocardial Infarction With ST-Segment Elevation After Prehospital Thrombolysis]. Kardiologiia. 2016;56(2):5-10. [Article in Russian].

6. Bonnefoy E, Steg PG, Boutitie F, Dubien PY, Lapostolle F, Roncalli J, et al. Comparison of primary angioplasty and prehospital fibrinolysis in acute myocardial infarction (CAPTIM) trial: a 5-year follow-up. Eur Heart J. 2009;30(13):1598-606. doi: 10.1093/eurheartj/ehp156.

7. Danchin N, Puymirat E, Steg PG, Goldstein P, Schiele F, Belle L, et al. Five-year survival in patients with ST-segmentelevation myocardial infarction according to modalities of reperfusion therapy: the French Registry on Acute STElevation and Non-ST-Elevation Myocardial Infarction (FAST-MI) 2005 Cohort. Circulation. 2014;129(16):1629-36. doi: 10.1161/CIRCULATIONAHA.113.005874.

8. Claeys MJ, de Meester A, Convens C, Dubois P, Boland $\mathrm{J}$, De Raedt $\mathrm{H}$, et al. Contemporary mortality differences between primary percutaneous coronary intervention and thrombolysis in ST-segment elevation myocardial infarction. Arch Intern Med. 2011;171(6):544-9. doi: 10.1001/ archinternmed.2011.57.

9. Westerhout CM, Bonnefoy E, Welsh RC, Steg PG, Boutitie F, Armstrong PW. The influence of time from symptom onset and reperfusion strategy on 1-year survival in ST-elevation myocardial infarction: a pooled analysis of an early fibrinolytic strategy versus primary percutaneous coronary intervention from CAPTIM and WEST. Am Heart J. 2011;161(2):283-90. doi: 10.1016/j.ahj.2010.10.033.

10. Siontis KC, Barsness GW, Lennon RJ, Holmen JL, Wright RS, Bell MR, Gersh BJ. Pharmacoinvasive and Primary Percutaneous Coronary Intervention Strategies in ST-Elevation Myocardial Infarction (from the Mayo Clinic STEMI Network). Am J Cardiol. 2016;117(12):1904-10. doi: 10.1016/j.amjcard.2016.03.036.

11. Steg PG, Bonnefoy E, Chabaud S, Lapostolle F, Dubien PY, Cristofini P, Leizorovicz A, Touboul P; Comparison of Angioplasty and Prehospital Thrombolysis In acute Myocardial infarction (CAPTIM) Investigators. Impact of time to treatment on mortality after prehospital fibrinolysis or primary angioplasty: data from the CAPTIM randomized clinical trial. Circulation 2003;108(23):2851-6.

12. Gershlick AH, Westerhout CM, Armstrong PW, Huber K, Halvorsen S, Steg PG, et al. Impact of a pharmacoinvasive strategy when delays to primary PCI are prolonged. Heart. 2015;101(9):692-8. doi: 10.1136/heartjnl-2014-306686.

13. Galasso G1, Schiekofer S, D’Anna C, Gioia GD, Piccolo R, Niglio T, Rosa RD, et al. No-reflow phenomenon: pathophysiology, diagnosis, prevention, and treatment.Areview of the current literature and future perspectives. Angiology. 2014;65(3):180-9. doi: 10.1177/0003319712474336.

14. Bouleti C, Mewton N, Germain S. The no-reflow phenomenon: State of the art. Arch Cardiovasc Dis. 2015;108(12):661-74. doi: 10.1016/j.acvd.2015.09.006.

15. Bohmer E, Hoffmann $\mathrm{P}$, Abdelnoor $\mathrm{M}$, Arnesen $\mathrm{H}$, Halvorsen S. Efficacy and safety of immediate angioplasty vs. ischemia-guided management after thrombolysis in acute myocardial infarction in areas with very long transfer distances results of the NORDISTEMI (NORwegian study on DIstrict treatment of ST-elevation myocardial infarction). J Am Coll Cardiol. 2010;55(2):102-10. doi: 10.1016/j.jacc.2009.08.007. 16. Borgia F, Goodman SG, Halvorsen S, Cantor WJ, Piscione F, Le May MR, et al. Early routine percutaneous coronary intervention after fibrinolysis vs. standard therapy in ST-segment elevation myocardial infarction: a meta-analysis. Eur Heart J. 2010;31(17):2156-69. doi: 10.1093/eurheartj/ ehq204.

17. D'Souza SP, Mamas MA, Fraser DG, Fath-Ordoubadi F. Routine early coronary angioplasty vs. ischaemiaguided angioplasty after thrombolysis in acute ST-elevation myocardial infarction: a meta-analysis. Eur Heart J. 2011;32(8):972-82. doi: 10.1093/eurheartj/ehq398. 